\title{
Evaluation of large stock unit equivalents for sheep
}

\author{
M.J. Herselman \\ Grootfontein ADI, Private Bag X529, Middelburg, 5900
}

\section{Introduction}

The applicability of Large Stock Unit equivalents (LSU's), as assigned to different sheep breeds by the Conservation of Agricultural Resources Act (Act 43 of 1983) (Department of Agricultural Economics and Marketing, 1985), has for many years been questioned in practice. This can possibly be attributed to the categorization of sheep into Woolen, Mutton, Dual Purpose and Karakul types which does not reflect real differences in body weight. According to the aforementioned act, one set of body weights and thus one set of LSU's are associated with each category, but differences in body weight among breeds of the same category are not taken into account. For example, both Merino and Afrino sheep are classified into the woolen sheep category (Meissner et al., 1983), hence the same LSU is used for both breeds. This does not recognize body weight differences of up to $20 \%$ between these two breeds. According to Meissner et al. (1983), the classification of livestock for the realistic prediction of a biologically defined Large Stock Unit is based on the energy requirements of the animal. Accordingly, all aspects which influence energy requirements, such as body weight, production level and reproductive status, should be reflected in LSU's. Energy requirements on which current LSU's for sheep are based were calculated by a combination of the methods of the ARC (1965) and Hofmeyr (1972).The objective of this paper is to evaluate the applicability of prescribed LSU equivalents for different sheep breeds.

\section{Material and Methods}

The production and reproduction data of Merino, Afrino and Dorper sheep, which were kept for a four-and-a-half year period at two different localities, namely, Vlekpoort near Hofmeyr in the Eastern Cape and Carnarvon Experimental station in the Northern Cape were used for this evaluation. At both localities, all three breeds were run as one flock (Snyman et al., 1991; Snyman et al., 2000). The energy requirements of the different breeds during different production stadia were calculated from the production and reproduction data (ARC, 1980). LSU's were calculated by dividing energy requirements (MJ ME/day) by a factor of $75 \mathrm{MJ}$ ME/day. The latter represents the daily ME requirement of a biologically defined Large Stock Unit (Meissner et al.,1983). For calculation of daily energy requirements, it was assumed that dry ewes gain $50 \mathrm{~g} / \mathrm{day}$ in body weight; lactating ewes lose $100 \mathrm{~g} /$ day in body weight; metabolizability (q) of energy of the feed which sheep select in the veld is 0.41 .

\section{Results and Discussion}

Body weight of ewes at mating was 50,65 and $66 \mathrm{~kg}$ for Merino, Afrino and Dorper sheep respectively, while 120 day weaning weight of lambs was 23.7, 32.2 and $33.4 \mathrm{~kg}$ for the respective breeds (Snyman et al., 2000). Pre-weaning growth rate was 196, 278 and $290 \mathrm{~g}$ /day for Merino, Afrino and Dorper lambs and post-weaning growth rate was 72, 89 and $88 \mathrm{~g}$ /day respectively. Body weight at one year of age was 41.3, 54.0 and $55.0 \mathrm{~kg}$ respectively. The production system which was followed in the trial, whereby all ewes were mated twice per year, limited the use of fecundity values for the purpose of this evaluation and therefore fecundity values of 1.2, 1.4 and 1.4 were used for Merino, Afrino and Dorper sheep in the calculation of milk production, ME requirements and LSU's of lactating ewes (ARC, 1980). Daily milk production, as calculated from fecundity and growth of lambs (ARC, 1980) was 1.368, 2.336 and 2.452 liter/day for Merino, Afrino and Dorper ewes respectively. The energy requirements and corresponding LSU's calculated from the foregoing production figures are shown in Table 1.

Table 1 Daily energy requirements and LSU's of three sheep breeds

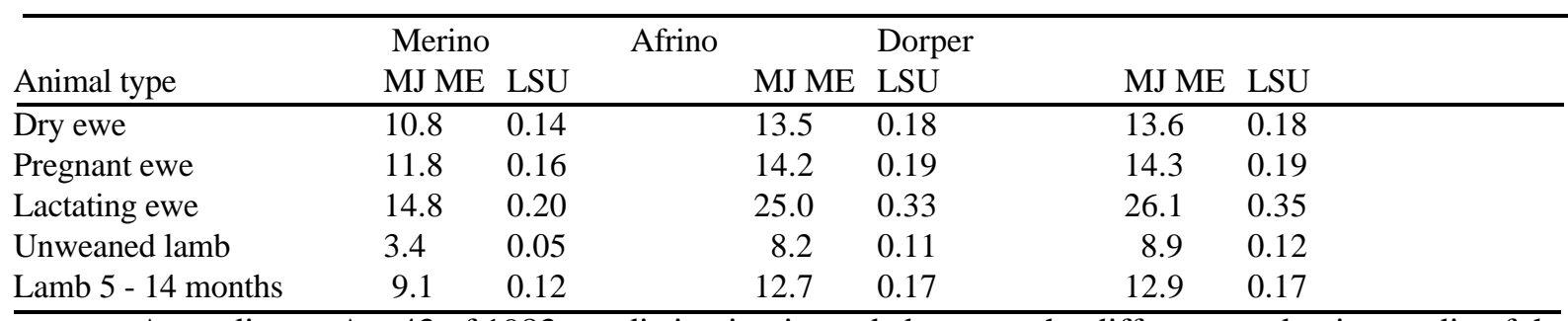

According to Act 43 of 1983, no distinction is made between the different production stadia of the ewe and 


\section{Short paper and poster abstracts: $38^{\text {th }}$ Congress of the South African Society of Animal Science}

therefore, the LSU's shown in Table 1 are not directly comparable with those found in the act. In this regard, it is presumed that the increased energy requirement during lactation was assigned to the lambs. A value for ewes comparable to the prescribed LSU's was also calculated and is presented in Table 2. This was obtained by combining the energy requirements for a dry ewe for 46 weeks and energy requirements during the last 6 weeks of pregnancy. The energy requirements for unweaned lambs in Table 1 is not in addition to that of the lactating ewe but reflects the increase in energy required by the ewe, expressed per lamb. In other words, the LSU's in Table 1 for lambs should not be used in conjunction with the LSU's for lactating ewes but rather together with the LSU's of a dry ewe. In Table 2, the prescribed LSU's are compared with the calculated LSU's of this study.

Table 2 LSU's of three sheep breeds as prescribed by Act 43 of 1983 and as calculated in this study

\begin{tabular}{|c|c|c|c|c|c|c|}
\hline \multirow[b]{2}{*}{ Animal type } & \multicolumn{2}{|c|}{ Merino } & \multirow[t]{2}{*}{ Afrino } & \multicolumn{3}{|c|}{ Dorper } \\
\hline & Study & Act & & Act & Study & Act \\
\hline Unweaned lamb & 0.05 & 0.05 & 0.11 & 0.05 & 0.12 & 0.08 \\
\hline Weaned lamb & 0.12 & 0.10 & 0.17 & 0.10 & 0.17 & 0.11 \\
\hline Ewe & 0.15 & 0.14 & 0.18 & 0.14 & 0.18 & 0.15 \\
\hline Ram & 0.19 & 0.19 & 0.23 & 0.19 & 0.23 & 0.23 \\
\hline Number of ewes* & 795 & 863 & 673 & 988 & 710 & 954 \\
\hline
\end{tabular}

* Calculated for a 3200 ha farm with a carrying capacity of 16 ha/LSU

Calculated LSU's for unweaned Dorper and Afrino lambs were considerably higher than the prescribed values (Table 2). The relative low LSU's prescribed by the act for unweaned Dorper and Afrino lambs are also not in accordance with energy requirements of lactating ewes (with milk production in access of two litre per day) which is approximately twice as high as that of dry ewes (ARC, 1980). The calculated LSU's for weaned lambs were also generally higher than the prescribed values especially in the breeds with relative high weaning weights. The difference between calculated and prescribed LSU's for ewes can be explained by differences in body weight between the sheep of this study and those on which the LSU's of the act were based. The number of ewes in Table 2 was calculated with the simulation models of Herselman et al. (1989). Using prescribed LSU's, the number of ewes which a farm of 200 LSU's can carry, is generally overestimated, especially for Afrino and Dorper sheep. The relative difference in ewe numbers is of special importance when producers are considering changing from one breed to another. Farmers usually change from wool sheep farming to mutton production and according to current legislation, more mutton ewes can be carried on the same size of land than wooled sheep ewes. As this study contradicts the latter, this indicates that breed changes by farmers may in many cases be detrimental to the natural resource. Notwithstanding the higher calculated LSU's for Dorper sheep, more Dorper ewes can be kept than Afrino ewes (Table 2) because of the fact that Afrino lambs have to stay for a longer period on the farm than Dorper lambs to become marketable. The reason for this is that Dorper lambs grow faster than Afrino lambs and are normally slaughtered at a lower body weight due to fat accumulation.

\section{Conclusion}

The results of this evaluation indicate towards certain shortcomings in current legislation regarding LSU's for sheep, which may impact detrimentally on the utilization and conservation of natural resources. The dangers associated with this justify a comprehensive survey of real differences in body weight and production among sheep breeds, whereby legislation can be revised. It is also concluded that the weight and production of sheep on a farm is of greater importance for the determination of the LSU's than the breed.

\section{References}

Agricultural Research Council, 1965. The nutrient requirements of Farm Livestock. No. 2, Ruminants. London; HMSO.

Agricultural Research Council, 1980. The nutrient requirements of Ruminant Livestock. Commonwealth Agricultural Bureaux, London.

Dept. Agric. Econ. \& Mark., 1985. Conservation of Agricultural Resources Act, 1983 (Act 43 of 1983). Government Gazette No R 2687, 6 December, 1985.

Herselman, M.J. et al., 1989. Proc. 28th SASAP Congress, Ermelo.

Hofmeyr, H.S., 1972. D.Sc (Agric) thesis, Univ. of Pretoria. 
Short paper and poster abstracts: $38^{\text {th }}$ Congress of the South African Society of Animal Science Meissner, H.H. et al., 1983. Tech. Comm., Dept Agric., No. 175.

Snyman, M.A. et al., 2000. Grootfontein Agric. (Submitted)

Snyman, M.A. et al., 1991. Proc. 30th SASAP Congress, Port Elizabeth. 